\title{
PARENTS' PERSPECTIVES ON SCHOOL AND FAMILY COOPERATION IN PRIMARY SCHOOLS: A CASE STUDY IN CHINA
}

\author{
YIN Xiaoyang \\ Faculty of Education, STGi University, Kota Damansara, Malaysia; \\ E-mail: yinxiaoyang1985@gmail.com \\ Gurnam Kaur Sidhu \\ Faculty of Education, SEGi University; Kota Damansara, Malaysia \\ E-mail: gurnamgurdial@segi.edu.my \\ P.K.Veloo \\ Faculty of Education, SEGi University; Kota Damansara, Malaysia; \\ E-mail: pkveloo@segi.edu.my
}

\begin{abstract}
family cooperation in primary schools in China. This study involved 100 randomly selected parents from two primary schools located in the urban district of Yin Chuan, Ning Xia Hui-Autonomous Region in China. Data was collected through a questionnaire and semi structured interviews. The findings in this study revealed that parents had a close relationship with their children, the teachers and the school. This close parent-teacher partnership also indicated a positive and significant relationship between parental involvement in school activities and children's academic achievement. This close relationship could perhaps be due to the fact that a majority of the parents in the survey were well educated and had only one child under China's one-child policy. Nevertheless, the findings further validate findings from other studies that close relationship between parents and the school is necessary for students' achievement.
\end{abstract}

Keywords: Parental involvement, School and family cooperation, Communication, teachers, school

\section{INTRODUCTION}

There is no denying that while the $21^{\text {st }}$ century has brought a lot of positive changes in the field of education, there is still one aspect that remains much to be desired, i.e. school and family partnership. The collaboration between school and family is important because the family unit is often the first educator for the child and it is the family that continues to influence the child's leaning and development. According to Dodson (2010), as first educators, the parents' role need to be recognized, respected and incorporated in the governance of schools and how education is delivered. This collaborative relationship is even more important especially in today's communities when both parents are working with little or no time for their children.

School and family cooperation refers to the collaborative relationship among parents, the school and the community. Together they form a partnership to work together for the betterment of the children and the community at large. These partnerships should however, view each partner as making equally valuable contributions with mutual trust, understanding and shared responsibility for the education of the children at school. Today, there is sufficient research evidence which has indicated that effective schools display high levels of cooperation between parental and community involvement. Thus, family involvement is often said to be a crucial factor for students' achievement regardless of social and cultural backgrounds.

There is sufficient evidence that suggests parental involvement positively influences students' achievement. More importantly, research has also shown that children whose parents are involved in their learning process, show good performance like better grades, improved attendance and higher qualification rates (Epstein, 1983). Additionally, good parent and family cooperation also results in children having better social skills and improved behavior. According to Levanda (2011) parental 
involvement includes a wide variety of actions parents take for the benefit of children's academic success at school. These include parenting style, parental expectations and aspirations, home rules and parental supervision; parents' attitudes towards children activities, helping with homework, visiting the school to talk to teachers, and beliefs regarding their children's education. Parents who are actively involved in school and family cooperative efforts learn how to set goals with their children.

The parental support of the children at home (e.g., emotional support, helping with homework, assistance with encouragement, and educational decisions) influences school success (Peterson, RubieDavies, Elley-Brown, Widdowson, Dixon and Irving 2011). Epstein (2001) noted that many parents are uninformed of homework assignments and ways to assist their children with homework and other curriculum related activities (Epstein, Sanders, Simon, Salians, Jansorn and Van, 2009). With a more collaborative partnership, parents can be a significant influence in encouraging students to complete their homework assignments and other activities, in setting personal goals for success in school and in preparing for postsecondary education or work. When parents are involved in academic activities, there may be an increased appreciation for the teaching profession and the role of the teacher (Epstein et al., 2009). Learning at home activities may escalate discussions within the home regarding school, class work, homework, and future plans (Epstein, 2001).

Patrikakou and Weissberg (1999) highlighted that research often has practical implications for intervention and they stressed that it is the 'quality' of parent-teacher cooperation rather than the 'quantity' of contacts, which relates to improved students' achievement and behavior. Besides that, they emphasized that teacher outreach to parents and parents' perceptions of how to welcome their opinions and involvement are much more important than demographic variables such as race or socioeconomic status in determining parent involvement. They proposed a program on three focal points for intervention to increase the awareness of issues involved in parent-teacher relationships. They are two-way, reciprocal, home-school communication; parent involvement in children's learning at home; and parent participation at school. Through work with parents and teachers, they identified seven important ingredients to partnership-building which they referred to as the "seven-P's philosophy". They are viewing the school and family partnership as a Priority, Planned effort (activities are carefully planned and implemented), Proactive and persistent communication (on goals and expectations). Positive style of communication, Personalized communication, Practical suggestions (on how parents can help their children) and systematic Program monitoring so that school and family-partnership activities can be further enhanced.

In China, since the implementation of the one-child policy, most families have only one child. As a result of the One-Child Policy and the aspiration for highly successful children, parents attach more importance to children's education. Many parents are eager to send their children to key schools, where the teachers are much more experienced in transitioning students to prestigious schools than the regular ones. Thus, parents have much more time and energy to spend with their children and to care for their study. Studies have also shown that well educated parents spend more time with schools and communities so that they can better guide their children's learning. All parents hope their children get a better education to secure a better job for the future. Nowadays with an increasing proportion of women in the family being educated, mothers are now able to contribute significantly to their children's learning. A study conducted by Pan, Gauvain, Liu, and Cheng (2006) noted that there were significant differences between Chinese and American parents of children aged between 6-12. Their findings revealed Chinese parents spend more time with their children compared to their American counterparts with regards to their children's studies. In China, most of the family's daily routes and communication is around education (Lin and $\mathrm{Fu}, 1990$ ). Generally, Chinese parents' academic expectation were found to be much higher than American parents'. Therefore, Chinese children are expected to achieve good grades and perform well academically, and academic success is regarded as a "family business" where each member has a stake in it (Tao and Hong, 2013).

\section{THE STUDY}

The main purpose of this study was to examine the parents' perspectives on school and family cooperation in China. More specifically, the study was aimed to explore parents' perceptions with regards to aspects such as their relationship with children, with the teachers and the school. The study also examined parents' perspectives with regards to their communication with school authorities and to what extent parents volunteered and collaborated in school programs.

The case study involved two randomly selected primary schools located in Ning Xia HuiAutonomous Region in part of Northwest in China. The study involved approximately 50 parents who were randomly selected from each school. The final sample comprised 100 parents. Further analysis 
into demographic variables indicated that $74 \%$ of the mothers were university graduates while the remaining $26 \%$ were high school graduates. On the other hand, $72 \%$ of the fathers were university graduates whilst $28 \%$ were high school graduates.

Data for the study was collected by using a mixed-methods which involved a questionnaire and semi-structured interviews. The items in the Parents' questionnaires were prepared based on literature in the field and it covered all the constructs which the study was aimed to explore. The questionnaire was validated by a panel of three experts from a university and a pilot test was conducted to establish the reliability which stood at 0.85 . This indicated that the questionnaire was reliable. The quantitative analysis was analyzed using both descriptive and inferential statistics using SPSS version 22. The semi structured interviews were conducted with three parents from each school due to time and logistics constraints. The qualitative analysis was analyzed using both inductive and deductive analysis to answer the research questions posed in the study.

\section{RESULTS AND DISCUSSION}

This section provides the findings of the study followed by a brief interpretation and discussion of parents' perspectives of school and family cooperation primary schools in China.

\subsection{Overall Perception of School-Family Cooperation}

The main aim of this study was to examine parents' perspectives on school and family cooperation in primary school. Findings displayed in Table 1 show the parents' perceptions of school and family cooperation based on the aspects explored in the study (Mean=3.90, $\mathrm{SD}=42.57$ ).

From the findings displayed in Table1 it can be seen that the parents were of the view that there exist good parent and child cooperation (Mean=4.02, $\mathrm{SD}=11.64)$ in these school. This indicates that parents do take an interest in their children's school work and keep track of their children's work. Furthermore, parents and teacher cooperation recorded a moderate level relationship (Mean=3.86, $\mathrm{SD}=7.56$ ) which is slightly below the "agree" score for this subscale. This shows that there is substantial cooperation between parents and teachers with respect to their children's work at school. They are also of the view that there is substantial cooperation between the school and parents (Mean=3.89, $\mathrm{SD}=7.28$ ). Their cooperation was further revealed in displaying that there is fairly good communication between the two parties $(\mathrm{M}=3.8, \mathrm{SD}=9.65)$.

Table1: Parents Overall Perceptions of School-Family Cooperation $(\mathrm{n}=100)$

\begin{tabular}{l|c|c}
\hline Perception of Parents & Mean & SD \\
\hline Parents Overall Perception & $\mathbf{3 . 9 0}$ & $\mathbf{4 2 . 5 7}$ \\
\hline Parents and their relationship with children & 4.02 & 11.64 \\
\hline Parents and their relationship with teachers & 3.86 & 7.56 \\
\hline Parents and their relationship with the school & 3.89 & 7.28 \\
\hline Parents' communication with school programs and students' progress & 3.86 & 9.65 \\
\hline
\end{tabular}

(Scale: $1=$ Strongly Disagree, 2= Disagree, 3= Almost Agree, 4= Agree, 5= Strongly Agree)

\subsection{Parents and their relationship with children}

When examining parents' perspectives of school and family cooperation, this study also explored parents' relationship with their children with regards to their school work study and school and family cooperation. Parents were required to respond to 15 items based on a Liker scale of 1 to 5 where a score of 1 indicated strong disagreement whilst a score of 5 indicated strong agreement. The findings indicated that parents are rather concerned and do take interest in their children's education $(\mathrm{M}=4.02$, $\mathrm{SD}=11.64)$. They do care and are concerned for their children's education as they do encourage their child to work hard to achieve good grades in school $(\mathrm{M}=4.28, \mathrm{SD}=.877)$ and encourage them to read a lot of books $(\mathrm{M}=4.33, \mathrm{SD}=.899)$. They also emphasized that they provide a good learning environment for their children $(\mathrm{M}=4.22, \mathrm{SD}=.811)$ and indicated that they were very happy when their child tries to do his/her best in school $(\mathrm{M}=4.28, \mathrm{SD}=.877)$. Besides that, they also indicated that they not only discuss the school day with their children $(\mathrm{M}=4.16, \mathrm{SD}=.811)$ but also discuss homework with their children $(\mathrm{M}=4.07, \mathrm{SD}=1.00)$. They also discuss their child's progress with the teacher $(\mathrm{M}=4.01$, $\mathrm{SD}=1.01)$. Based on the results it showed that from the activities of school and family cooperation, more and more parents are involved in various forms of activities in their children study on a daily 
basis. Nevertheless, a fair level of agreement was seen with regards to drawing up a plan of study for their children $(\mathrm{M}=3.64 \mathrm{SD}=1.04)$ and taking them for after-school tutoring program $(\mathrm{M}=3.67$, $\mathrm{SD}=1.11$ ). Parents also indicated a moderate level of agreement with them participating and joining their children in school events and activities $(\mathrm{M}=3.80, \mathrm{SD}=.853)$. This means that parents do make some time to attend and participate in the different types of activities organized by the school.

The above findings were also corroborated during the interview sessions. All the parents interviewed stressed that they do make time for their children and keep a close tab on their homework and school activities. For example Parent A emphasized that she "sits with my child every evening and help him with his homework" whilst parent D pointed out that he "has drawn up a time table for my daughter and I make sure she keeps herself in line with it according to the schedule, and there is sufficient enough time for her to play games on the internet and time for her to do her homework and study."

This findings that revealed that there is good parental involvement at home, especially with parents regularly asking their children about homework and helping them with homework and this without doubt has a positive relationship with children's academic achievement. This finding is also in line with the work conducted by Sui-Chu and Williams (1996) who found that, the involvement at home, especially parents discussing schoolwork and helping children plan their programs, had the strongest impact on positive schooling outcomes.

\subsection{Parents and their relationship with teachers}

Another aspect explored in this study was the relationship between parents and teachers. The findings indicated that parents acknowledged the importance of having a close relationship with teachers. They also stressed that they do work rather closely with their children's teachers $(\mathrm{M}=3.86 \mathrm{SD}=7.56)$ and do make an effort to see the teacher if they feel that their child has some problems in learning $(\mathrm{M}=3.93, \mathrm{SD}=.945)$. This was clearly indicated because a majority of the parents stressed that often discuss with the teacher their child's study in order to have a better understanding of their child $(\mathrm{M}=4.11, \mathrm{SD}=.941)$.Parents also agreed that they have attended at least one Meet-the-Parent session this year( $\mathrm{M}=3.99, \mathrm{SD}=.915)$ indicating that they are very much involved in school curriculum matters. The parents further articulated that they not only share with the teachers some of the effective strategies used at home $(\mathrm{M}=3.88, \mathrm{SD}=.977)$ but were also willing to assist their child's teacher in class $(\mathrm{M}=3.70, \mathrm{SD}=.930)$. Based on the results it showed that parents have good relationship with teachers with regards to school and family cooperation. Moreover, parents' communication with teachers was recorded as high as they do attend the parents' meeting, and they often discuss with the teachers, kinds of ways and strategies to educate children.

Similar sentiments were also recorded during the interview sessions. All six parents interviewed had highlighted the importance of having a good relationship with their child's teachers. Parent $\mathrm{C}$ emphasized that "I work very closely with my daughter's teacher and I see her often to make sure my daughter has no learning difficulties. If she is not sure about something I usually will talk to her teacher. Her teacher is exceptional, because she will help me with techniques and suggestions as to how I can help and deal with my child to improve herself in academics and non-academics skills, and to create good interaction between the teacher and herself among her peers. And to make herself adopted with psychological, social, emotional, intellectual balance and well being during her studies which is one of the fundamental aspect of a good teacher who supports the parent teacher interrelationship".

Other research studies such as a study conducted by Aslan (2016) also highlighted the importance of parent and teacher cooperation where parents who continually communicated with teachers, were able to establish effective communication and share students' problems (with teachers). More importantly, parents who worked closely with their children's teachers and school administrators were regarded as more successful. Epstein et al, (2009) reiterate that the school often provide information and ideas to parents on how to help students at home, including helping children with homework, completing course-related activities, making learning decisions and plans, and school also providing the student's requirements and expectations for each course to parents. Therefore, working closely with teachers, can assist parents in meeting their responsibilities as parents by providing activities that increase their knowledge and strengthen their skills in an effort to influence their child's growth.

\subsection{Parents and their relationship with the school}


The next dimension investigated was parents' perspectives of their relationship with school as a whole - i.e. relationship with school administrators, school authorities and school programs. In this section, parents were required to respond to ten (10) items which were again based on a 5-point Liker scale. The results indicated that parents were involved in school activities and worked rather closely with their children's school $(\mathrm{M}=3.50, \mathrm{SD}=7.56)$. They also discuss their children's learning with the school in order to understand their children better $(\mathrm{M}=3.93, \mathrm{SD}=.945)$. Parents also indicated that they were involved in school activities as this would provide them with opportunities to better understand the strategies put forward by the school to assist their child $(\mathrm{M}=3.97, \mathrm{SD}=.846)$. The parents further indicated that they are satisfied with the curriculum design of the school $(\mathrm{M}=3.74, \mathrm{SD}=.860)$ and agreed that the school organizes useful workshops for parents time to time $(\mathrm{M}=3.68, \mathrm{SD}=.941)$. They were also aware of most of the information in the message/communication book $(\mathrm{M}=3.95, \mathrm{SD}=1.00)$ and interview sessions also pointed out that all of them found the information good as it helped to update them on school activities and curriculum matters. Parents also agreed that they have attended at least one school program $(\mathrm{M}=3.95, \mathrm{SD}=.868)$ and this was further validated during interviews. Parent E agreed that she has attended "all school functions organized by the school and it included events such as school reading day, sports day and school theatrical performances. She also looked forward to being invited to share her experiences in class in class with her child.

Based on the results it showed that parents have a good relationship with school. The finding revealed that positive and healthy communication between school and family and the establishment of a state of cooperation at the first stage of primary education is thought to be of great importance in contributing to the future life success of students (Aslan, 2016). School activities that may strengthen parents' understanding of school life and development could include activities such as parenting skills, improving home conditions that may support learning, parent education workshops, and home visits (Epstein, 2001).

\subsection{Parents' communication with school}

The last dimension explored was parents' communication with the school. The findings revealed that the school ensures that there is a formal conference with parents at least once a year and the parents agreed that they communicate closely with their children's teachers $(\mathrm{M}=3.86 \mathrm{SD}=1.59)$, especially when the school teacher contacts parents when their child has academic or behavior problems (Mean=4.09, $\mathrm{SD}=.922$ ). This is clearly indicated because a majority of the parents indicated that they often communicate with the teacher about child's study so as to the school teacher establishes clear two-way channels for communications between family and school $(\mathrm{M}=4.02, \mathrm{SD}=.909)$. Parents also agreed that the school teachers have built a good communication channel, which is beneficial to discuss with parents $(\mathrm{M}=3.99, \mathrm{SD}=.870)$. In addition, the parents further conformed that the school teacher guides parents with relevant skills as to how to monitor and discuss homework with their child $(\mathrm{M}=3.89, \mathrm{SD}=.919)$. Data also showed that the school and principals communicate well with parents how they can step their involvement and value to the school $(\mathrm{M}=3.86, \mathrm{SD}=.947)$. Out of the ten items on communication with the school, the item that recorded the highest mean score was "the school teacher conducts a formal conference with me at least once a year"( $\mathrm{M}=4.10, \mathrm{SD}=.915)$ whilst the low mean score was for "the school teacher conducts an orientation program for parents" $(\mathrm{M}=3.53, \mathrm{SD}=$. 926).Nevertheless, both these scores reflect that parents communicated well with the school and have a high level of positive communication channel working both ways. Interview sessions also revealed that all parents involved and willing to establish a two-way communication channel with the teachers and the school as a whole.

Findings from other studies have also shown that communication, whether written or oral, gives parents a better understanding of policies, procedures and programs within the school, which allows for additional support of the school. Effective dialogue "develops out of a growing trust, a mutuality of concern, and an appreciation of contrasting perspectives" (Ozmen, Akuzum, Zincirli, and Selcuk, 2016). As parents communicate with the school they typically become more comfortable and satisfied with the school and the teachers (Epstein et al., 2009). As a result of effective and positive communication with staff, teachers, and administrators, parents are able to encourage a successful educational experience for their children and may become more actively involved (Epstein, 2001). But to negotiate these issues parents can benefit from effective communication with the school by having increased knowledge of policies, procedures, and programs within the school, allowing the parents to provide additional support in the educational experience. As parents communicate with the school they 
typically become more comfortable and satisfied with the school and the teachers (Epstein et al., 2009).

\subsection{Correlation between Parents' Perspective of School and Family Cooperation and Student Achievement}

The final aspect examined in this study was the relationship between parents' perspective of school and family cooperation and student achievement. This aspect was investigated using Pearson productmoment correlation coefficient. The findings are shown in Table 2 and from the findings we can see that there is a strong positive correlation between parents' perspectives and student achievement $r=$ $0.82, \mathrm{n}==100, p<0.001$, confirming that high level of parents' perception is associated with high achievement of the students.

Table 2: Correlation between Parents' Perspective of School and Family Cooperation and student Achievement

\begin{tabular}{l|l|l}
\hline Variables & $\begin{array}{l}\mathrm{P} \text { a } \mathrm{r} \text { e } \mathrm{n} \mathrm{t} \mathrm{s} \\
\text { 'Perspective }\end{array}$ & Achievement \\
\hline Parents' Perspective & 1.00 & $0.820 * * *$ \\
\hline Student' Achievements & $0.820 * * *$ & 1.00 \\
\hline & $* * * p<0.001$
\end{tabular}

The view is supported by other studies and researchers. For example, Henderson and Berla (1994) noted that children who interact with their parents on schooling matters had high completion rates of their homework, better grades and test scores, and more self-directed behavior. It seems that when the parents monitor homework, encourage participation in extracurricular activities, are active in parentsteacher associations, and help children develop plans for their future; children are more likely to respond and do well in school (Cotton and Wikelund, 1989). Also, these findings are consistency with Porumbu and Necsoi (2013) who found that parental involvement in the particular arena of children's schooling has benefited from a multidimensional conceptualization such as dedication in monitoring learning and providing resources to the child within the educational domain. In addition, the results reveal a positive and significant correlation between mothers' school involvement and academic performance of children.

\section{CONCLUSION}

In conclusion it can be summarized that the parents have a rather positive and good relationship with their children $(\mathrm{M}=4.02)$, the school $(\mathrm{M}=3.89)$, the teachers $(\mathrm{M}=3.86)$ and they have a good and positive two-way communication with the school $(\mathrm{M}=3.86)$. All this positivity could probably be because of the one-child policy in China. A majority (more than 95\%) of the parents in this survey have only one-child and close to $75 \%$ of them possess a university education. This study also indicated that there is a positive correlation between parent and school cooperation and student achievement. All this bear testimony that school and parents must form effective partnerships so that positive student achievement can be realized.

Finally, it cannot be denied that the small sample size of 100 parents from only two primary schools do not lend weight to generalize the findings for all primary schools in China. Nevertheless, it cannot be denied that this study has to a certain extent help to shed some light on parents" perspectives on school and family partnership with regards to their relationship with their children, the teachers and the school.

\section{REFERENCES}

Aslan, D. (2016). Primary School Teachers'Perception on Parental Involvement: A Qualitative Case Study. International Journal of Higher Education, 5(2):131.

Cotton, K. and Wikelund, K. R. (1989). Parent involvement in education, School improvement research series, 6(3): 17-23.

Dodson, M. (2010). Closing the Gap in Education? Improving outcomes in Southern World Societies, Australian National University (p.1-10).

Epstein, J. L. (1983). Longitudinal effects of family-school-person interactions on student outcomes, Research in sociology of education and socialization, 4: 101-128. 
Epstein, J. L. (2001). School, family, and community partnerships: Preparing educators and improving schools, NASSP Bulletin, 85 :(627).

Epstein, J. L., Sanders, M. G., Simon, B. S., Salinas, K. C., Jansorn, N. R., and Van Voorhis, F. L. (2009). School, family, and community partnerships: Your handbook for action. Corwin Press.

Henderson, A. T and Berla, N. (1994). A new generation of evidence: The family is critical to student achievement (A report from the National Committee for Citizens in Education). Washington, DC: Center for Law and Education.

Levanda, O. (2011). Parental involvement in school: A test of Hoover-Dempsey and Sandler's model among Jewish and Arab parents in Israel, Children and Youth Services Review, 33(6):927-935.

Lin, C. Y. C., and Fu, V. R. (1990). A comparison of child-rearing practices among Chinese, immigrant Chinese, and Caucasian-American parents, Child development, 61(2):429-433.

Ozmen, F., Akuzum, C., Zincirli, M., and Selcuk, G. (2016). The Communication Barriers between Teachers and Parents in Primary School s. Eurasian Journal of Educational Research, 66: 26-46.

Pan, Y., Gauvain, M., Liu, Z., and Cheng, L. (2006) American and Chinese parental involvement in young children's mathematics learning. Cognitive Development, 21(1): 17-35.

Patrikakou, E. N., and Weissberg, R.P. (1999) The Seven P's of School-Family Partnerships", Education Week, 18 (21): 34-36.

Peterson, E. R., Rubie-Davies, C. M., Elley-Brown, M. J., Widdowson, D. A., Dixon, R. S., and Irving, E. S. (2011). Who is to Blame? Students, Teachers and Parents Views on who is Responsible for Student Achievement, Research in Education, 86 (1):1-12.

Porumbu, D., and Necsoi, D. V. (2013). Relationship between parental involvement, attitude and children's school achievement, Procedia-Social \& Behavioral Sciences, 76: 706-710.

Sui-Chu, E. H., and Williams, J. D. (1996). Effects of parental involvement on eighth-grade achievement. Sociology of Education, 69(2): 126-141.

Tao, V. Y., and Hong, Y. Y. (2013). When academic achievement is an obligation: Perspectives from social-oriented achievement motivation, Journal of Cross Cultural Psychology, 45(1):110-136. 